\title{
Neuregulin 1 gene and variations in perceptual aberration of schizotypal personality in adolescents
}

\author{
HSIAO-FAN LIN ${ }^{1}$, YU-LI LIU ${ }^{2}$, CHIH-MIN LIU ${ }^{3}$, SHUEN-IU HUNG ${ }^{4}$, \\ HAI-GWO HWU ${ }^{1,3}$ AND WEI J. CHEN ${ }^{1,3 *}$ \\ ${ }^{1}$ Institute of Epidemiology, College of Public Health, National Taiwan University, Taipei, Taiwan; \\ ${ }^{2}$ Department of Medical Research, National Taiwan University Hospital, Taipei, Taiwan; ${ }^{3}$ Department of \\ Psychiatry, National Taiwan University Hospital and College of Medicine, National Taiwan University, Taipei, \\ Taiwan; ${ }^{4}$ National Genotyping Center, Institute of Biomedical Sciences, Academia Sinica, Taipei, Taiwan
}

\begin{abstract}
Background. We test the hypothesis that the neuregulin 1 (NRG1) gene at chromosome 8p22-p12, which has been implicated as a susceptibility gene to schizophrenia, is associated with variations in schizotypal personality in non-clinical populations.
\end{abstract}

Method. A randomly selected sample of 905 adolescents were assessed for their personality features using the Perceptual Aberration Scale (PAS) and the Schizotypal Personality Questionnaire (SPQ) and genotyped for three single nucleotide polymorphisms (SNP8NRG221533, rs3924999, and rs2954041) at the NRG1 gene. Relations between the three genetic variants and continuous schizotypal personality scores were evaluated using ANOVA for single-locus analyses and haplotype trend regression test for multi-locus analyses.

Results. Single locus analysis showed that the A allele of rs3924999, a functional polymorphism in exon 2, had the largest effect size and exhibited a prominent allele-dose trend effect for the PAS score. Haplotype analyses using the haplotype trend regression test indicated that the A allele of rs3924999 was mainly responsible for the association with the PAS but not with the SPQ or its three factors, and the magnitude of significance was not strengthened by the combination of this allele with adjacent locus.

Conclusions. Our study provides the first evidence for the association of $N R G 1$ with schizotypal personality and indicates a possible role of NRG1 in the genetic etiology of schizophrenia through perceptual aberrations.

\section{INTRODUCTION}

The concept of schizotypal personality was first postulated as a preclinical genetic expression for schizophrenia (Rado, 1953; Meehl, 1962). Family, adoption, and twin studies in both categorical (Kendler et al. 1993; Torgersen et al. 1993; Kety et al. 1994) and dimensional (Lenzenweger \& Loranger, 1989; Kendler \& Hewitt, 1992; Chapman et al. 1994) approaches

* Address for Correspondence: Dr Wei J. Chen, Institute of Epidemiology, College of Public Health, National Taiwan University, 1 Jen-Ai Rd, Sec. 1, Taipei 100, Taiwan.

(Email:weijen@ha.mc.ntu.edu.tw) have indicated that schizotypal personality is genetically related to schizophrenia and may reflect some aspects of the genetic predisposition to schizophrenia. The heritability for schizotypal personality was found to be substantial (Lyons et al. 1995). Factor-analytic studies have revealed that schizotypal personality may consist of three factors, i.e. positive (psychotic-like cognitive and perceptual experiences), negative (anhedonia and interpersonal dysfunction), and disorganization (Vollema \& van den Bosch, 1995; Venables \& Rector, 2000), each with differential associations with biobehavioral traits (Chen et al. 1997; Barrantes-Vidal et al. 2003). 
Taken together, schizotypal personality has been proposed as an endophenotype for schizophrenia and may be closer to the expressions of schizophrenia genes (Gottesman \& Gould, 2003). Assessing the relation of the candidate genes for schizophrenia to schizotypal personality may help shed light on the etiological pathway for the genes. Recent studies for identifying susceptibility genes for schizophrenia seemed to have accumulated more replicable findings with biologically plausible mechanism in pathogenesis being postulated (Owen et al. 2004). One of these findings is the newly discovered gene Neuregulin 1 (NRGl), which involves regulation of $N$-methyl-D-aspartate (NMDA) receptors and has role in neurodevelopment and synaptic plasticity, on chromosome 8p22-p12 in a study in Iceland (Stefansson et al. 2002). An appealing feature for the association of $N R G 1$ with schizophrenia is its replications in a variety of populations, including independent studies in Scotland (Stefansson et al. 2003), England (Williams et al. 2003), China (Yang et al. 2003; Zhao et al. 2004), and Ireland (Corvin et al. 2004), although not in a highdensity family study of schizophrenia in Ireland (Thiselton et al. 2004). However, the first three studies (Stefansson et al. 2002, 2003; Williams et al. 2003) did not find a clear pathogenic mutation and all the markers of a 7-marker haplotype were within the 5'-promoter to the first intron. Yang et al. (2003) extended the covering range of single nucleotide polymorphisms (SNPs) by randomly selecting two more SNPs, rs3924999 in the second exon (a functional polymorphism with Arg 38 Gln) and rs2954041 in the fifth intron, in addition to the most significant SNP (SNP8NRG221533) found by Stefansson et al. (2002). All three SNPs showed linkage disequilibrium (LD) with schizophrenia, and so did the haplotypes of the three SNPs (Yang et al. 2003).

Thus far there has been no study examining the role of the NRG1 gene in schizotypal personality. Our objective was to investigate associations between polymorphisms in NRG1 and variations in schizotypal personality features in adolescents randomly selected from the school population. Our rationale was twofold. First, because features of schizotypal personality diminish with age (Chen et al. 1997), young people might be better than older ones to obtain consistent schizotypal personality scores. Second, adolescents with schizotypal personality usually have not yet been diagnosed with a personality disorder or influenced by diagnosisrelated intervention or social stigma than their adult counterparts. Hence, adolescents with schizotypal personality might be relatively conducive to identifying the effect of the $N R G 1$ gene without being confounded by age or therapeutic interventions if it indeed exists.

\section{METHOD}

\section{Subjects}

The subjects in this study were 905 (459 girls and 446 boys) junior high-school students in Taipei City selected through a multiple-stage sampling procedure. Because junior high-school education is compulsory basic education in Taiwan, this student body represents an unselective population, especially for those in public schools. The sampling of the participants has been described in detail elsewhere (Lin et al. 2000). Briefly, we stratified the 71 public junior high schools in Taipei City in 1996 by educational levels of the residents into the three groups, and randomly selected one school from each group. Then, three classes were randomly selected from each grade $(1-3)$ in each of the three participating schools. In total, there were 971 students from 27 classes eligible for this study. After informed written consent was obtained from the students and their parents, $905(93 \%)$ junior high-school students completed the self-report questionnaire and 878 $(90 \%)$ did a mouth rinse with $4 \%$ sucrose to offer buccal cells. The study was approved by the institutional review board of the College of Public Health, National Taiwan University.

\section{Measurement instruments}

The participants were asked to complete a questionnaire inquiring demographic features and schizotypal personality features, including the Perceptual Aberration Scale (PAS; Chapman et al. 1978), Schizotypal Personality Questionnaire (SPQ; Raine, 1991), and Junior Eysenck Personality Questionnaire (JEPQ; Eysenck, 1975). The PAS contains 35 true-false items enquiring about the experience of bodyimage distortions, while the SPQ contains 74 true-false items that were grouped into nine 
subscales corresponding to all nine criteria of the schizotypal personality disorder in the DSM-III-R. The two parts were intermingled to minimize the potential offensiveness of some questions regarding aberrations in bodily perception, as suggested by Chapman et al. (1978). The reliability and validity of both scales in the Taiwanese population have been reported in detail elsewhere (Chen et al. 1997, 1998). Briefly, both the SPQ and PAS were translated from English to Chinese by means of two-stage translation. The 1-week test-retest reliability coefficient $(0.86$ for the SPQ and 0.80 for the PAS) and the internal consistency alphas $(0.95$ for the SPQ and 0.84 for the PAS) in a sample of 30 subjects were satisfactory. Furthermore, a combination of the PAS and SPQ has been found to have good validity in screening for schizophrenia-related personality disorders in the community adults (Chen et al. in press).

In the JEPQ, which contains 81 'yes-no' selfreport items, there is an $\mathrm{L}$ scale consisting of 20 items that was presumed to measure the 'desirability response'. The establishment and psychometric properties of the Chinese version of the JEPQ was reported previously (Kuo et al. 2004). For this study, we used the score on L as a control for potential unreliable responders.

\section{Genomic DNA preparation}

Buccal mucosa cells were collected from each participant by mouth-washing for at least $10 \mathrm{~s}$ with a $10 \mathrm{ml}$ solution of $4 \%$ sucrose (Lench et al. 1988; Hayney et al. 1996). The procedure of obtaining DNA from the mouth-wash sample has been reported elsewhere (Chen et al. 1999). Briefly, by a series of centrifugation, discarding the supernatant, the sediment was stored at $-70{ }^{\circ} \mathrm{C}$ until used for DNA extraction. The genomic DNA was extracted by following the standard protocol of a commercial kit, QIAamp Mini kit (Qiagen, Chatsworth, CA, USA).

\section{SNP genotyping}

Genotyping of the three SNPs of NRG1 selected for this study, SNP8NRG221355, rs3924999, and rs2954041, was conducted by using the method of matrix-assisted laser desorption/ ionization-time-of-flight mass spectrometry (MALDI-TOF MS). The specific PCR primers and extension primers were designed by using SpectroDesigner software (Sequenom, San
Diego, CA, USA) according to the sequences available in the GenBank (http://www.ncbi. nlm.nih.gov/GeneBank; AF491780). Genomic DNA of $2.5 \mathrm{ng}$ was used as template and a DNA fragment (100-300 bp) encompassing the SNP site was amplified by the polymerase chain reaction (PCR) according to the manufacturer's instruction. After PCR amplification, the MassEXTEND (Sequenom) reaction was performed by incubating the termination mixtures, i.e. dideoxynucleotide triphosphate (ddNTP) and deoxynunleotide triphosphate (dNTP). A MassEXTEND probe which sat just next to the SNP site, Thermosequenase (Amersham Biosciences, Little Chalfont, Buckinghamshire, $\mathrm{UK}$ ), and appropriate ddNTP/dNTP mixture were added to the above reaction mixture. Allele-specific extended products were obtained by the GeneAmp 9700 thermocycler (ABI, Foster City, CA, USA) under the conditions of 55 cycles of denaturing at $94{ }^{\circ} \mathrm{C}$ for $5 \mathrm{~s}$, annealing at $52{ }^{\circ} \mathrm{C}$ for $5 \mathrm{~s}$, and extension at $72{ }^{\circ} \mathrm{C}$ for $5 \mathrm{~s}$.

After desalting the reaction product with SpectroCLEAN, $\sim 15 \mathrm{nl}$ were spotted onto the SpectroCHIP using the SpectroPOINT (Sequenom). These primer extension products were then analyzed by the MALDI-TOF MS in the fully automated mode. After acquired spectra were transferred to the MassARRAY system (Sequenom), genotype calling was performed by applying the SpectroTYPER software (Sequenom) and a set of digital filters were optimized automatically for mass spectra of DNA.

\section{Statistical analysis}

A confirmatory factor analysis of the SPQ was conducted using the PROC CALIS of the software package SAS (version 8.2 for Windows; SAS Institute Inc., Cary, NC, USA). We adopted the three-factor model of Raine et al. (1994) as the following: (a) Cognitive-Perceptual Dysfunction (ideas of reference, magical thinking, unusual perceptual experience and paranoid ideation); (b) Interpersonal Dysfunction (social anxiety, no close friends, constricted affect, and paranoid ideation); and (c) Disorganization (odd behavior and odd speech). Following two previous studies on the confirmatory factor analysis of the SPQ (Raine et al. 1994; Chen et al. 1997), the fitness of the model was evaluated by three indices: the goodness of fit, the adjusted 
goodness of fit, and the normed fit index. Values of goodness of fit (Cole, 1987) and normed fit index (Bentler \& Bonett, 1980) of $>0.9$ and an adjusted goodness-of-fit value of $>0.8$ (Cole, 1987) indicate a good fit.

Because the distribution of the PAS and the SPQ scores were skewed, these personality scores were first normalized using the PROC RANK and then standardized using the PROC STANDARD of the SAS. The transformation reduced nonnormality and standardized scores to unity variance and zero mean. The relations between genotypes in each SNP marker and the standardized normal scores of schizotypal personality were assessed using ANOVA (one-way or twoway, depending on whether to adjust for sex effect) or ANCOVA (to adjust for age). For those with a significant effect, effect sizes were calculated: a value of 0.2 was considered a small effect and that of 0.5 a medium effect (Cohen, 1987). Possible dose-response effect of an allele was further evaluated by regressing the schizotypal scores on the number of the allele in each genotype with sex and age as covariates. In each marker, three comparisons between the individual factors of the SPQ were dealt with Bonferroni correction by controlling for the testing of multiple phenotypes.

We assessed the Hardy-Weinberg equilibrium by the $\chi^{2}$ test for each marker. Haplotype frequencies were estimated using the EM algorithm and whether there was LD was examined using the $\chi^{2}$ test or exact test based on 10000 permutations, if some haplotype frequency was rare. Potential associations between the set of haplotypes and schizotypal personality features were examined via haplotype trend regression with permutation-based hypothesis testing procedures as described by Zaykin et al. (2002), which yields an $F$ test for the significance and a mean trait value for each haplotype in relation to the trait under test. Following the suggestion in a recent review (Wall \& Pritchard, 2003), two important pairwise measures of LD, $\left|D^{\prime}\right|$ and $r^{2}$, were then calculated. High LD was defined as a $r^{2}$ of $>1 / 3$ as suggested by Ardlie et al. (2002) or a $\left|D^{\prime}\right|$ of $>0.7$ as suggested by Gabriel et al. (2002). All these genetic analyses were performed by using the computer program PowerMarker version 3.09 (Liu \& Muse, 2004). To examine whether there was population stratification in our sample, which might lead to a false-positive results, a $Z$ statistics using a panel of SNPs (Lee, 2003) was calculated.

\section{RESULTS}

The confirmatory factor analysis revealed that the three-factor model of the SPQ had a good fit to the data as indicated by the high values of relevant indices, i.e. 0.92 for the goodness-of-fit index, 0.85 for the adjusted goodness-of-fit index, and 0.89 for the normed fit index. There were moderate but significant correlations between the PAS and the SPQ $(r=0.57)$, Cognitive-Perceptual Dysfunction $(r=0 \cdot 55)$, Interpersonal Dysfunction $(r=0 \cdot 37)$, and Disorganization $(r=0.53)$. The mean age of the participating students was $14 \cdot 0$ years (s.D. $=0 \cdot 9$ ), ranging from 12.0 to 16.9 years. Mean scores for these schizotypal personality features were 5.4 (s.D. $=4.4), 23.8$ (s.D. $=11.9$ ), 11.5 (s.D. $=$ $6 \cdot 2), 10 \cdot 4$ (s.D. $=6 \cdot 4)$ and $4.9($ s.D. $=3 \cdot 5)$ for the PAS, SPQ, Cognitive-Perceptual Dysfunction, Interpersonal Dysfunction, and Disorganization respectively. There were no differences between boys and girls except that girls had a higher mean SPQ total score $\left(F_{1,902}=8 \cdot 62\right.$, $p=0.0034)$ and Cognitive-Perceptual Dysfunction $(p \leqslant 0.05$ for the $t$ test) than boys. Moreover, the SPQ total score increased with age $\left(F_{1,902}=3 \cdot 83, p=0 \cdot 05\right)$.

To examine the potential impact of unreliable responders on the results, we conducted a separate analysis by deleting those individuals with an extreme score on the L scale of the JEPQ. The mean score of $\mathrm{L}$ scale in the sample was 8.8 (S.D. $=3.6$ ) for boys and 9.6 (S.D. $=3.7$ ) for girls; hence 11 boys and 19 girls were excluded because of a score $>2$ S.D. However, the distribution of the PAS, SPQ, Cognitive-Perceptual Dysfunction, Interpersonal Dysfunction, and Disorganization remained almost unchanged for each sex, and the pattern and magnitude of their associations with the three SNPs of $N R G 1$ were similar to those of the total sample. Thus, only the results for the total sample were presented for the subsequent analyses.

The number of successful genotypings for each of the three SNP markers among the 878 students' DNA and the corresponding genotype counts and allele frequencies were as follows: 867 for SNP8NRG221533 (counts: $\mathrm{C} / \mathrm{C}=254$, $\mathrm{C} / \mathrm{T}=455, \mathrm{~T} / \mathrm{T}=158$; frequencies: $\mathrm{C}=0 \cdot 56$, 
Table 1. The distributions of the PAS and SPQ scores by the genotype of each of the three SNPS of NRG1

\begin{tabular}{|c|c|c|c|c|c|c|c|c|}
\hline \multirow[b]{2}{*}{ Genotype } & \multirow[b]{2}{*}{$n$} & \multicolumn{2}{|c|}{ PAS } & \multicolumn{2}{|c|}{ SPQ } & \multirow{2}{*}{$\begin{array}{l}\text { Cognitive- } \\
\text { perceptual } \\
\text { dysfunction } \\
\text { Mean (s.D.) }\end{array}$} & \multirow{2}{*}{$\begin{array}{c}\text { Interpersonal } \\
\text { dysfunction } \\
\text { Mean (s.D.) }\end{array}$} & \multirow[b]{2}{*}{$\begin{array}{c}\text { Disorganization } \\
\text { Mean (s.D.) }\end{array}$} \\
\hline & & Mean (s.D.) & $\begin{array}{l}\text { Effect } \\
\text { size }\end{array}$ & Mean (s.D.) & $\begin{array}{l}\text { Effect } \\
\text { size }\end{array}$ & & & \\
\hline \multicolumn{9}{|c|}{ SNP8NRG221533 } \\
\hline $\mathrm{C} / \mathrm{C}$ & 250 & $5 \cdot 2(4 \cdot 0)$ & & $24 \cdot 9(12 \cdot 2)$ & & $12 \cdot 0(6 \cdot 0)$ & $11 \cdot 0(6 \cdot 6)$ & $5 \cdot 0(3 \cdot 5)$ \\
\hline $\mathrm{C} / \mathrm{T}$ & 453 & $5 \cdot 3(4 \cdot 3)$ & & $23 \cdot 2(11 \cdot 8)$ & & $11 \cdot 1(6 \cdot 3)$ & $10 \cdot 3(6 \cdot 3)$ & $4 \cdot 8(3 \cdot 5)$ \\
\hline $\mathrm{T} / \mathrm{T}$ & 157 & $5 \cdot 5(5 \cdot 0)$ & & $23 \cdot 1(11 \cdot 7)$ & & $11 \cdot 5(6 \cdot 2)$ & $9 \cdot 7(6 \cdot 1)$ & $4 \cdot 9(3 \cdot 5)$ \\
\hline Trend test ${ }^{\mathrm{a}}$ & & $p=0 \cdot 84$ & & $p=0 \cdot 10^{\mathrm{b}}$ & & $p=0 \cdot 30^{\mathrm{c}}$ & $p=0.07$ & $p=0.64$ \\
\hline \multicolumn{9}{|l|}{ Rs3924999 } \\
\hline $\mathrm{A} / \mathrm{A}$ & 533 & $5 \cdot 6(4 \cdot 5) \dagger$ & $0 \cdot 27$ & $24 \cdot 5(12 \cdot 3) \div$ & $0 \cdot 13$ & $11 \cdot 7(6 \cdot 4)$ & $10 \cdot 8(6 \cdot 5)$ & $5 \cdot 1(3 \cdot 6)$ \\
\hline $\mathrm{A} / \mathrm{G}$ & 293 & $4.9(3.9) \dagger$ & $0 \cdot 10$ & $22 \cdot 4(11 \cdot 4) \div$ & -0.07 & $11 \cdot 1(6 \cdot 0)$ & $9 \cdot 8(6 \cdot 2)$ & $4 \cdot 4(3 \cdot 2)$ \\
\hline $\mathrm{G} / \mathrm{G}$ & 37 & $4 \cdot 4(4 \cdot 4) \dagger$ & & $23 \cdot 1(10 \cdot 3) \dagger$ & & $10 \cdot 7(5 \cdot 6)$ & $10 \cdot 2(5 \cdot 9)$ & $5 \cdot 0(3 \cdot 6)$ \\
\hline Trend test $\mathrm{a}^{\mathrm{a}}$ & & $p=0 \cdot 004$ & & $p=0 \cdot 03^{\mathrm{b}}$ & & $p=0 \cdot 11^{\mathrm{c}}$ & $p=0.08$ & $p=0.05$ \\
\hline \multicolumn{9}{|l|}{ Rs2954041 } \\
\hline $\mathrm{G} / \mathrm{G}$ & 295 & $5 \cdot 4(4 \cdot 3)$ & & $23 \cdot 4(11 \cdot 6)$ & & $11 \cdot 3(6 \cdot 1)$ & $10 \cdot 1(6 \cdot 1)$ & $4 \cdot 9(3 \cdot 5)$ \\
\hline $\mathrm{G} / \mathrm{T}$ & 417 & $5 \cdot 3(4 \cdot 1)$ & & $24 \cdot 1(12 \cdot 0)$ & & $11 \cdot 5(6 \cdot 2)$ & $10 \cdot 9(6 \cdot 6)$ & $4.9(3.5)$ \\
\hline $\mathrm{T} / \mathrm{T}$ & 153 & $5 \cdot 6(5 \cdot 1)$ & & $23 \cdot 8(12 \cdot 3)$ & & $11 \cdot 8(6 \cdot 4)$ & $9 \cdot 9(6 \cdot 3)$ & $5 \cdot 1(3 \cdot 5)$ \\
\hline \multirow[t]{2}{*}{ Trend test ${ }^{\mathrm{a}}$} & & $p=0.92$ & & $p=0.52^{\mathrm{b}}$ & & $p=0 \cdot 43^{c}$ & $p=0.96$ & $p=0.53$ \\
\hline & & $\begin{array}{l}\mathrm{a} \text { Based on } \\
\mathrm{b} \text { Further a } \\
\mathrm{c} \text { Further ac } \\
\dagger p=0.01 \mathrm{fc} \\
+p=0.05 \mathrm{fc}\end{array}$ & $\begin{array}{l}\text { tandar } \\
\text { ted for } \\
\text { ed for } \\
\text { e one- } \\
\text { e ANC }\end{array}$ & $\begin{array}{l}\text { d normal sco } \\
\text { and sex. } \\
\text { ANOVA }\left(F_{2} \text {, }\right. \\
\text { A with sex an }\end{array}$ & $\begin{array}{l}\text { of each } \\
\text { 0.05 }=4 \cdot \\
\text { ge adjus }\end{array}$ & $\begin{array}{l}\text { sonality scale. } \\
\text { ent }\left(F_{2,858} ; 0.05\right.\end{array}$ & & \\
\hline
\end{tabular}

$\mathrm{T}=0 \cdot 44$ ), 870 for rs3924999 (counts: $\mathrm{A} / \mathrm{A}=538$, $\mathrm{A} / \mathrm{G}=295, \mathrm{G} / \mathrm{G}=37$; frequencies: $\mathrm{A}=0.79$, $\mathrm{G}=0 \cdot 21$ ), and 871 for rs2954041 (counts: $\mathrm{G} /$ $\mathrm{G}=298, \mathrm{G} / \mathrm{T}=419, \mathrm{~T} / \mathrm{T}=154$; frequencies: $\mathrm{G}=0.58, \mathrm{~T}=0.42$ ). All the distributions of the three markers did not deviate from the Hardy-Weinberg equilibrium. In the ANOVA testing for the personality score difference among the three genotypes for each marker, only the marker on the second exon, rs3924999, revealed a significant association with the PAS and the SPQ total scores (Table 1). All those three comparisons between separate factors of the SPQ in each marker were dealt with by Bonferroni correction. In terms of the effect size, the genotype A/A of rs3924999 had a greatest effect on the PAS as compared with that of the genotype $\mathrm{G} / \mathrm{G}$, and that of the genotype $\mathrm{A} / \mathrm{G}$ in between. In contrast, the effect size of rs3924999 genotypes on the SPQ total scores was less linear, with heterozygous effect being the lowest. In the testing for trend, only the genotypes of rs3924999 had a significant trend effect on both the PAS and the SPQ total scores.

In terms of the LD between the three SNPs, the pairwise $\left|D^{\prime}\right|$ between marker 2 (rs3924999) and marker 3 (rs2954041) was moderately high, that between marker 1 (SNP8NRG221533) and marker 2 modest, and almost not existing between marker 1 and marker 3 (Table 2). Despite the significant LDs between adjacent markers, all the $r^{2}$ 's and the differences between estimated haplotype frequency and expected haplotype frequency were minimal.

In examining the relationship between individual haplotypes and each of the schizotypal personality features, the software program PowerMarker 3.0 did not allow for the adjustment of other covariates. Thus, in addition to the standardized normal scores for the personality scales, $z$ scores adjusted for correlated demographic features were also used for analysis. The adjusted $z$ score was calculated using the method described in Chen et al. (1998) for the SPQ total score (adjusted for age and sex) and the Cognitive-Perceptual Dysfunction score (adjusted for sex). Because the results of both unadjusted $z$ scores and adjusted $z$ scores were very similar, only the results of unadjusted scores are presented in Table 2. According to haplotype trend regression, only the PAS scores were related to the haplotypes consisting of SNP8NRG221533 and rs3924999 $(p=0.01)$ as well as the haplotypes of rs3924999 and 
Table 2. Estimated haplotype frequency and mean schizotypal scores in each of two-locus haplotypes

\begin{tabular}{|c|c|c|c|c|c|c|c|}
\hline \multirow{2}{*}{\multicolumn{2}{|c|}{ Two-locus haplotype }} & \multirow{3}{*}{$\begin{array}{l}\begin{array}{l}\text { Haplotype } \\
\text { frequency }\end{array} \\
(n=857)\end{array}$} & \multicolumn{5}{|c|}{ Mean score } \\
\hline & & & \multirow[t]{2}{*}{ PAS } & \multirow[t]{2}{*}{ SPQ } & \multirow[t]{2}{*}{ Factor 1} & \multirow[t]{2}{*}{ Factor 2} & \multirow[t]{2}{*}{ Factor 3} \\
\hline Marker 1 & Marker 2 & & & & & & \\
\hline C & A & $0 \cdot 45$ & $5 \cdot 5$ & $24 \cdot 5$ & $11 \cdot 7$ & $10 \cdot 8$ & $5 \cdot 1$ \\
\hline $\mathrm{T}$ & A & $0 \cdot 34$ & $5 \cdot 6$ & $23 \cdot 4$ & $11 \cdot 4$ & $10 \cdot 1$ & $4 \cdot 9$ \\
\hline $\mathrm{T}$ & G & $0 \cdot 11$ & $5 \cdot 1$ & $22 \cdot 7$ & $11 \cdot 2$ & $9 \cdot 8$ & $4 \cdot 7$ \\
\hline $\mathrm{C}$ & G & $0 \cdot 10$ & $4 \cdot 6$ & $22 \cdot 6$ & $10 \cdot 9$ & $10 \cdot 0$ & $4 \cdot 4$ \\
\hline$\left|D^{\prime}\right|$ & & $0 \cdot 1292$ & & & & & \\
\hline$r^{2}$ & & $0 \cdot 0056$ & & & & & \\
\hline$\chi^{2}(p \text { value })^{\mathrm{a}}$ & & $9 \cdot 6(0 \cdot 002)$ & & & & & \\
\hline $\mathrm{HTR}^{\mathrm{b}}$ & & & $p=0 \cdot 01$ & $p=0 \cdot 07$ & $p=0 \cdot 20$ & $p=0 \cdot 11$ & $p=0 \cdot 14$ \\
\hline Marker 2 & Marker 3 & $(n=858)$ & & & & & \\
\hline A & G & $0 \cdot 41$ & $5 \cdot 5$ & $24 \cdot 1$ & $11 \cdot 6$ & $10 \cdot 6$ & $5 \cdot 0$ \\
\hline A & $\mathrm{T}$ & $0 \cdot 38$ & $5 \cdot 5$ & $24 \cdot 0$ & $11 \cdot 6$ & $10 \cdot 4$ & $5 \cdot 0$ \\
\hline $\mathrm{G}$ & $\mathrm{T}$ & $0 \cdot 04$ & $4 \cdot 8$ & $23 \cdot 1$ & $11 \cdot 3$ & $10 \cdot 3$ & $4 \cdot 5$ \\
\hline $\mathrm{G}$ & $\mathrm{G}$ & $0 \cdot 17$ & $4 \cdot 9$ & $22 \cdot 6$ & $11 \cdot 0$ & $9 \cdot 8$ & $4 \cdot 6$ \\
\hline$\left|D^{\prime}\right|$ & & $0 \cdot 5611$ & & & & & \\
\hline$r^{2}$ & & $0 \cdot 0608$ & & & & & \\
\hline$\chi^{2}(p \text { value })^{\mathrm{a}}$ & & $104 \cdot 4(<0 \cdot 001)$ & & & & & \\
\hline $\mathrm{HTR}^{\mathrm{b}}$ & & & $p=0 \cdot 03$ & $p=0 \cdot 29$ & $p=0 \cdot 40$ & $p=0 \cdot 32$ & $p=0 \cdot 16$ \\
\hline Marker 1 & Marker 3 & $(n=855)$ & & & & & \\
\hline $\mathrm{C}$ & $\mathrm{T}$ & $0 \cdot 23$ & $5 \cdot 2$ & $24 \cdot 6$ & $11 \cdot 9$ & $10 \cdot 7$ & $5 \cdot 1$ \\
\hline $\mathrm{T}$ & G & $0 \cdot 26$ & $5 \cdot 6$ & $23 \cdot 4$ & $11 \cdot 4$ & $10 \cdot 0$ & $4 \cdot 9$ \\
\hline $\mathrm{C}$ & $\mathrm{G}$ & $0 \cdot 32$ & $5 \cdot 2$ & $23 \cdot 8$ & $11 \cdot 4$ & $10 \cdot 6$ & $4 \cdot 8$ \\
\hline $\mathrm{T}$ & $\mathrm{T}$ & $0 \cdot 19$ & $5 \cdot 3$ & $23 \cdot 1$ & $11 \cdot 2$ & $10 \cdot 1$ & $4 \cdot 8$ \\
\hline$\left|D^{\prime}\right|$ & & $0 \cdot 0037$ & & & & & \\
\hline$r^{2}$ & & 0 & & & & & \\
\hline$\chi^{2}(p \text { value })^{\mathrm{a}}$ & & $0.02(0 \cdot 89)$ & & & & & \\
\hline HTR $^{\mathrm{b}}$ & & & $p=0.13$ & $p=0 \cdot 19$ & $p=0 \cdot 19$ & $p=0.42$ & $p=0.31$ \\
\hline
\end{tabular}

Marker 1=SNP8NRG221533; Marker 2=rs3924999; Marker 3=rs2954941; Factor 1=Perceptual-Cognitive Dysfunction; Factor $2=$ Interpersonal Dysfunction; Factor $3=$ Disorganization.

a $\chi^{2}$ test statistic for the null hypothesis that the pairwise LDs are zero, $\mathrm{df}=1$.

b Haplotype trend regression test for the standardized normal scores.

rs2954041 $(p=0 \cdot 03)$. All the other schizotypal traits were not associated with the two-locus haplotypes.

For the three-locus haplotype analysis, LD was significant, with the four haplotypes that contain the allele A of rs3924999 having a frequency of $>20 \%$ and the remaining four a frequency of $<10 \%$ (Table 3). Comparing the mean scores of each schizotypal trait for the haplotypes, only the PAS scores were associated with the haplotypes, in which the haplotypes with the A allele of rs3924999 had higher PAS scores than those without. Similar results were obtained when adjusted $z$ scores were used for the analysis and hence are not shown in the table.

In terms of the detection for hidden population stratification, the $Z$ statistic on the basis of the three SNPs was only $1 \cdot 00$, which did not reach statistical significance $(p=0 \cdot 159$, onesided).

\section{DISCUSSION}

Among the three SNPs examined in this study, it was the A allele of rs3924999 that had the largest effect size and exhibited a prominent allele-dose trend effect on both the PAS and the SPQ total scores. However, in terms of the trend effect of A allele, the pattern for the PAS was more consistent (the mean score for heterozygote $\mathrm{A} / \mathrm{G}$ was in-between of the two homozygotes) than that for the SPQ total (heterozygote $\mathrm{A} / \mathrm{G}$ had the lowest mean score). Furthermore, the two-locus haplotypes that contained rs3924999, either SNP8NRG221533rs3924999 or rs3924999-rs2954041, were significantly associated with scores on the PAS. In contrast, there was no such association between the haplotypes and the SPQ total scores. In the three-locus haplotype analysis, it turned out that only the PAS was associated with SNPs. The inconsistency in the association between 
Table 3. Estimated haplotype frequency and mean schizotypal scores in each of three-locus haplotypes $(n=852)$

\begin{tabular}{|c|c|c|c|c|c|c|c|}
\hline \multirow[b]{2}{*}{ Haplotype $^{\mathrm{a}}$} & \multicolumn{2}{|c|}{ Haplotype frequency } & \multicolumn{5}{|c|}{ Mean score } \\
\hline & $\begin{array}{l}\text { Estimated } \\
\text { frequency }\end{array}$ & $\begin{array}{l}\text { Expected } \\
\text { frequency }\end{array}$ & PAS & SPQ & Factor 1 & Factor 2 & Factor 3 \\
\hline $\mathrm{C} / \mathrm{G} / \mathrm{T}$ & $0 \cdot 02$ & $0 \cdot 05$ & $5 \cdot 1$ & $23 \cdot 6$ & $11 \cdot 4$ & $10 \cdot 7$ & $4 \cdot 5$ \\
\hline $\mathrm{C} / \mathrm{G} / \mathrm{G}$ & 0.09 & $0 \cdot 07$ & $4 \cdot 4$ & $22 \cdot 4$ & $10 \cdot 8$ & $9 \cdot 9$ & $4 \cdot 4$ \\
\hline $\mathrm{T} / \mathrm{A} / \mathrm{T}$ & $0 \cdot 16$ & $0 \cdot 15$ & $5 \cdot 3$ & $23 \cdot 2$ & $11 \cdot 2$ & $10 \cdot 1$ & $4 \cdot 8$ \\
\hline $\mathrm{T} / \mathrm{A} / \mathrm{G}$ & $0 \cdot 17$ & $0 \cdot 20$ & $5 \cdot 7$ & $23 \cdot 7$ & $11 \cdot 5$ & $10 \cdot 2$ & $5 \cdot 0$ \\
\hline $\mathrm{T} / \mathrm{G} / \mathrm{T}$ & $0 \cdot 02$ & $0 \cdot 04$ & $4 \cdot 6$ & $22 \cdot 7$ & $11 \cdot 2$ & $10 \cdot 1$ & $4 \cdot 4$ \\
\hline $\mathrm{T} / \mathrm{G} / \mathrm{G}$ & $0 \cdot 09$ & $0 \cdot 05$ & $5 \cdot 2$ & $22 \cdot 8$ & $11 \cdot 2$ & $9 \cdot 7$ & $4 \cdot 7$ \\
\hline $\mathrm{C} / \mathrm{A} / \mathrm{T}$ & $0 \cdot 22$ & $0 \cdot 19$ & $5 \cdot 5$ & $24 \cdot 6$ & $11 \cdot 9$ & $10 \cdot 7$ & $5 \cdot 1$ \\
\hline $\mathrm{C} / \mathrm{A} / \mathrm{G}$ & $0 \cdot 24$ & $0 \cdot 26$ & $5 \cdot 4$ & $24 \cdot 4$ & $11 \cdot 6$ & $11 \cdot 0$ & $5 \cdot 0$ \\
\hline Exact $p$ value ${ }^{\mathrm{b}}$ & $p<0.001$ & & & & & & \\
\hline $\mathrm{HTR}^{\mathrm{c}}$ & & & $p=0 \cdot 02$ & $p=0 \cdot 30$ & $p=0 \cdot 45$ & $p=0.41$ & $p=0 \cdot 48$ \\
\hline
\end{tabular}

Factor 1 = Perceptual-Cognitive Dysfunction; Factor $2=$ Interpersonal Dysfunction; Factor $3=$ Disorganization.

a Allele of haplotype presented in order of SNP8NRG221533, rs3924999, and rs2954941.

b Testing for multi-locus association by the exact test based on 10000 permutations ( $p$ value cut-off $=0 \cdot 05$ )

${ }^{c}$ Haplotype trend regression test for the standardized normal scores.

rs3924999 and the SPQ total score was further indicated by the lack of any association between the SNP and the three factors of the SPQ. Thus, it appears that rs3924999 is consistently associated with the schizotypal personality features measured by the PAS but not by the SPQ or its three factors.

Both the PAS and the Cognitive-Perceptual Dysfunction of the SPQ are thought to be representative of so-called 'positive schizotypy'. However, the correlation between the PAS and the Cognitive-Perceptual Dysfunction scores in this study was not high, which is consistent with a previous study (Chen et al. 1997). Furthermore, subscales constituting the Cognitive-Perceptual Dysfunction were not limited to the unusual perceptual experience. Based on the three-factor model (Raine et al. 1994), some other parts, such as ideas of reference, magical thinking, and paranoid ideation, were also included. Thus, the PAS and CognitivePerceptual Dysfunction are likely to represent two different schizotypal personality traits. It might then lead to their differential relations to the genetic variation in NRG1 gene. As indicated by the non-differential correlations between the PAS and the three factors of the SPQ, the finding also calls into question whether perceptual aberration should be pooled with other aspects of positive schizotypy to form a single factor. Further research in other samples is warranted to clarify this issue.
Overall, our results seem to indicate that the association of NRG1 with the PAS was mainly due to the effect of rs3924999, whereas the effects of the other two SNPs were negligible. If all three SNPs are not the true susceptibility locus for schizotypal personality but are merely nearby the true one, then a multipoint haplotype formed by these SNPs would likely lead to a more significant association with the schizotypal personality than the individual SNP because of inclusion of all pairwise and higher-order disequilibria terms (Zaykin et al. 2002). However, the multi-locus haplotype analyses in this study did not lead to an increase in the significance of the associations compared with that of the single-locus analysis. This is further supported by the findings of low values of $r^{2}$ between the adjacent SNPs.

The SNP rs3924999 is in the 12 position within the second exon of the NRG1 gene (Yang et al. 2003). Its $\mathrm{G}$ to $\mathrm{A}$ base change causes amino-acid transfer from arginine to glutamine, although the change is conservative in terms of the isoforms of NRG1. Whether the functional polymorphism of rs3924999 in protein level is pathogenic requires further study. Several lines of research have provided circumstantial evidence for the involvement of $N R G 1$ in psychopathology. First, NRG1 affects expression and function of several central nervous system (CNS) neurotransmitter receptors. The 
NRG1-knockout mice were found to have deficiency in glutamatergic innervation and hyperactivity in behavioral tests, which was partially reversed with clozapine (Stefansson et al. 2002). The pattern was similar to the defects in glutamatergic neurotransmission caused by $\mathrm{N}$-methyl-D-aspartate receptor hypofunction, which was associated with psychosis in schizophrenic patients and positive schizotypy in normal individuals (Krystal et al. 1999). Second, NRG1 regulates radial glial cells, whose abnormality may lead to wrong placement and impaired connectivity of neurons (Schmid et al. 2003). The deficiency in glial growth factors caused by NRG1 may lead to synaptic destabilization, which has been hypothesized to be involved in the etiology of schizophrenia (Moises et al. 2002). Moreover, other NRG1 signaling in the CNS suppresses the induction of long-term potentiation, a form of synaptic plasticity (Huang et al. 2000). Intriguingly, higher scores on items pooled from different scales pertaining to perceptual unreality in college students were found to be related to the timing of extreme puberty (Gruzelier \& Kaiser, 1996), which was postulated to be related to abnormal synaptic plasticity. Taken together, our finding of the association between the perceptual aberration aspect of schizotypy and the NRGI gene is compatible with the possible biological function of the $N R G 1$ gene.

Some other features of this study are worthy of note. First, we adopted a quantitative approach for the analysis of schizotypal personality features. This may provide more statistical power than a categorical approach relying on an arbitrarily defined cut-off point. Second, our sample was free from population stratification bias since the detection for the population stratification turned out to be not significant. Nevertheless, it should also be kept in mind that the allele associated with an increased PAS score is very common (a frequency of 0.79 ) and the effect size is modest at best $(0 \cdot 1-0 \cdot 27)$. Given the lack of proved functional meaning of the polymorphism, the association might not necessarily be etiological.

Some limitations in this study should be kept in mind in interpreting our results. First, because the age range of this study was small, we do not know whether the association be- tween the SNP marker rs3924999 and the scores on the PAS will stay the same in adulthood when both the PAS and the SPQ scores decreased with age (Chen et al. 1997). Future investigation in adults is warranted. Second, our sample was limited to non-clinical population and whether the finding extends to people with more extreme schizotypy needs replication.

In conclusion, among the three SNPs of $N R G 1$ examined in this study, the SNP marker on exon 2, rs3924999, was consistently associated with the scores on the PAS but not with the SPQ in a randomly selected sample of adolescents. Single-locus as well as multi-locus haplotype analyses indicate that the A allele of rs3924999 was mainly responsible for the association with the PAS, and the magnitude of significance was not strengthened by the combination of this allele with adjacent locus. Possible biological function of the NRG1 gene is compatible with the association of the rs3924999 with the perceptual aberrations measured by the PAS. We, therefore, conclude that NRG1 may be a candidate gene for variations in perceptual aberration of schizotypal personality and may have a role in the genetic etiology of schizophrenia through perceptual aberrations.

\section{ACKNOWLEDGEMENTS}

This study was supported by grants from the National Science Council, Taiwan (NSC862314-B002-328, NSC87-2314-B002-290, NSC 91-2314-B-002-216; NSC91-3112-B-002-011), National Health Research Institute, Taiwan (NHRI-EX-92-9113PP). The authors are grateful for the assistance of the Core Laboratory of Population Genetic Polymorphisms at the NTU Center for Genomic Medicine for DNA extraction, Mr. S. Y. Yang for his supervision in laboratory procedures, the National Genotyping Center at Academia Sinica for SNP genotyping, and the principals and teachers of the participating schools for their help in recruiting students.

\section{DECLARATION OF INTEREST}

None. 


\section{REFERENCES}

Ardlie, K. G., Kruglyak, L. \& Seielstad, M. (2002). Patterns of linkage disequilibrium in the human genome. Nature Reviews Genetics 3, 299-309.

Barrantes-Vidal, N., Fananas, L., Rosa, A., Caparros, B., Dolors Riba, M. \& Obiols, J. E. (2003). Neurocognitive, behavioural and neurodevelopmental correlates of schizotypy clusters in adolescents from the general population. Schizophrenia Research 61, 293-302.

Bentler, P. M. \& Bonett, D. G. (1980). Significance tests and goodness of fit in the analysis of covariance structures. Psychological Bulletin 88, 588-606.

Chapman, L. J., Chapman, J. P., Kwapil, T. R., Eckblad, M. \& Zinser, M. C. (1994). Putatively psychosis-prone subjects 10 years later. Journal of Abnormal Psychology 103, 171-183.

Chapman, L. J., Chapman, J. P. \& Raulin, M. L. (1978). Body-image aberration in schizophrenia. Journal of Abnormal Psychology 87, 399-407.

Chen, W. J., Chang, H.-W., Wu, M.-Z., Lin, C. C. H., Chang, C., Chiu, Y. N. \& Soong, W. T. (1999). Diagnosis of zygosity by questionnaire and polymarker polymerase chain reaction in young twins. Behavior Genetics 29, 115-123.

Chen, W. J., Hsiao, C. K., Hsiao, L. L. \& Hwu, H. G. (1998). Performance of the Continuous Performance Test among community samples. Schizophrenia Bulletin 24, 163-174.

Chen, W. J., Hsiao, C. K. \& Lin, C. C. (1997). Schizotypy in community samples: the three-factor structure and correlation with sustained attention. Journal of Abnormal Psychology $\mathbf{1 0 6}$ 649-654.

Chen, W. J., Liou, Y.-L., Liu, S.-K., Chang, C.-J. \& Hwu, H.-G. (in press). Using schizotypy scales in the detection of schizophrenia-related personality disorders in the community. Psychiatry Research.

Cohen, J. (1987). Statistical Power Analysis for the Behavioral Sciences (revised edn), pp. 24-27. Lawrence Erlbaum Associates: Hillsdale, NJ.

Cole, D. A. (1987). Utility of confirmatory factor analysis in test validation research. Journal of Consulting and Clinical Psychology 55, 584-594.

Corvin, A. P., Morris, D. W., McGhee, K., Schwaiger, S., Scully, P., Quinn, J., Meagher, D., St Clair, D., Waddington, J. L. \& Gill, M. (2004). Confirmation and refinement of an 'at-risk' haplotype for schizophrenia suggests the EST cluster, Hs.97362, as a potential susceptibility gene at the Neuregulin-1 locus. Molecular Psychiatry 9, 208-212.

Eysenck, H. J. \& Eysenck, S. B. G. (1975). Manual of the Eysenck Personality Questionnaire. Hodder and Stoughton: London.

Gabriel, S. B., Schaffner, S. F., Nguyen, H., Moore, J. M., Roy, J., Blumenstiel, B., Higgins, J., DeFelice, M., Lochner, A., Faggar, M., Liu-Cordero, S. N., Rotimi, C., Adeyemo, A., Cooper, R., Ward, R., Lander, E. S., Daly, M. J. \& Altshuler, D. (2002). The structure of haplotype blocks in the human genome. Science 296, 2225-2229.

Gottesman, I. I. \& Gould, T. D. (2003). The endophenotype concept in psychiatry: etymology and strategic intentions. American Journal of Psychiatry 160, 636-645.

Gruzelier, J. H. \& Kaiser, J. (1996). Syndromes of schizotypy and timing of puberty. Schizophrenia Research 21, 183-194.

Hayney, M. S., Poland, G. A. \& Lipsky, J. J. (1996). A noninvasive 'swish and spit' method for collecting nucleated cells for HLA typing by PCR in population studies. Human Heredity 46, $108-111$.

Huang, Y. Z., Won, S., Ali, D. W., Wang, Q., Tanowitz, M., Du, Q. S., Pelkey, K. A., Yang, D. J., Xiong, W. C., Salter, M. W. \& Mei, L. (2000). Regulation of neuregulin signaling by PSD-95 interacting with ErbB4 at CNS synapses. Neuron 26, 443-455.

Kendler, K. S. \& Hewitt, J. (1992). The structure of self-report schizotypy in twins. Journal of Personality Disorders 6, 1-17.

Kendler, K. S., McGuire, M., Gruenberg, A. M., O'Hare, A., Spellman, M. \& Walsh, D. (1993). The Roscommon Family
Study: III. Schizophrenia-related personality disorders in relatives. Archives of General Psychiatry 50, 781-788.

Kety, S. S., Wender, P. H., Jacobsen, B. \& Ingraham, L. J. (1994). Mental illness in the biological and adoptive relatives of schizophrenic adoptees: replication of the Copenhagen study in the rest of Denmark. Archives of General Psychiatry 51, $442-455$.

Krystal, J. H., D'Souza, D. C., Petrakis, I. L., Belger, A., Berman, R. M., Charney, D. S., Abi-Saab, W. \& Madonick, S. (1999). NMDA agonists and antagonists as probes of glutamatergic dysfunction and pharmacotherapies in neuropsychiatric disorders. Harvard Review of Psychiatry 7, 125-143.

Kuo, P. H., Chih, Y. C., Soong, W. T., Yang, H. J. \& Chen, W. J. (2004). Assessing personality features and their relations with behavioral problems in adolescents: tridimensional personality questionnaire and junior Eysenck personality questionnaire. Comprehensive Psychiatry 45, 20-28.

Lee, W. C. (2003). Detecting population stratification using a panel of single nucleotide polymorphisms. International Journal of Epidemiology 32, 1120.

Lench, N., Stanier, P. \& Williamson, R. (1988). Simple noninvasive method to obtain DNA for gene analysis. Lancet 1, 1356-1358.

Lenzenweger, M. F. \& Loranger, A. W. (1989). Detection of familial schizophrenia using a psychometric measures of schizotypy. Archives of General Psychiatry 46, 902-907.

Lin, C. C. H., Chen, W. J., Yang, H. J., Hsiao, C. K. \& Tien, A. Y. (2000). Performance on the Wisconsin Card Sorting Test among adolescents in Taiwan: norms, factorial structure, and relation to schizotypy. Journal of Clinical and Experimental Neuropsychology 22, 69-79.

Liu, K. \& Muse, S. (2004). PowerMarker: new genetic data analysis software. Version 3.0. Free program distributed by the author over the internet (http://www.powermarker.net).

Lyons, M. J., Toomey, R., Faraone, S. V., Kremen, W. S., Yeung, A. S. \& Tsuang, M. T. (1995). Correlates of psychosis proneness in relatives of schizophrenic patients. Journal of Abnormal Psychology 104, 390-394.

Meehl, P. E. (1962). Schizotaxia, schizotypy, schizophrenia. American Psychologist 17, 827-838.

Moises, H. W., Zoega, T. \& Gottesman, I. I. (2002). The glial growth factors deficiency and synaptic destabilization hypothesis of schizophrenia. BMC Psychiatry 2, 8.

Owen, M. J., Williams, N. M. \& O'Donovan, M. C. (2004). The molecular genetics of schizophrenia: new findings promise new insights. Molecular Psychiatry 9, 14-27.

Rado, S. (1953). Dynamics and classification of disordered behavior. American Journal of Psychiatry 110, 406-416.

Raine, A. (1991). The SPQ: a scale for the assessment of schizotypal personality based on DSM-III-R criteria. Schizophrenia Bulletin 17, 555-564.

Raine, A., Reynolds, C., Lencz, T., Scerbo, A., Triphon, N. \& Kim, D. (1994). Cognitive-perceptual, interpersonal, and disorganized features of schizotypal personality. Schizophrenia Bulletin 20, 191-201.

Schmid, R. S., McGrath, B., Berechid, B. E., Boyles, B., Marchionni, M., Sestan, N. \& Anton, E. S. (2003). Neuregulin 1-erbB2 signaling is required for the establishment of radial glia and their transformation into astrocytes in cerebral cortex. Proceedings of the National Academy of Sciences USA 100 , $4251-4256$

Stefansson, H., Sarginson, J., Kong, A., Yates, P., Steinthorsdottir, V., Gudfinnsson, E., Gunnarsdottir, S., Walker, N., Petursson, H., Crombie, C., Ingason, A., Gulcher, J. R., Stefansson, K. \& St Clair, D. (2003). Association of neuregulin 1 with schizophrenia confirmed in a Scottish population. American Journal of Human Genetics 72, 83-87.

Stefansson, H., Sigurdsson, E., Steinthorsdottir, V., Bjornsdottir, S., Sigmundsson, T., Ghosh, S., Brynjolfsson, J., Gunnarsdottir, S., Ivarsson, O., Chou, T. T., Hjaltason, O., Birgisdottir, B., Jonsson, H., Gudnadottir, V. G., Gudmundsdottir, E., Bjornsson, A., 
Ingvarsson, B., Ingason, A., Sigfusson, S., Hardardottir, H., Harvey, R. P., Lai, D., Zhou, M., Brunner, D., Mutel, V., Gonzalo, A., Lemke, G., Sainz, J., Johannesson, G., Andresson, T., Gudbjartsson, D., Manolescu, A., Frigge, M. L., Gurney, M. E., Kong, A., Gulcher, J. R., Petursson, H. \& Stefansson, K. (2002). Neuregulin 1 and susceptibility to schizophrenia. American Journal of Human Genetics 71, 877-892.

Thiselton, D. L., Webb, B. T., Neale, B. M., Ribble, R. C., O'Neill, F. A., Walsh, D., Riley, B. P. \& Kendler, K. S. (2004). No evidence for linkage or association of neuregulin-1 (NRG1) with disease in the Irish study of high-density schizophrenia families (ISHDSF). Molecular Psychiatry 9, 777-783.

Torgersen, S., Onstad, S., Skre, I., Edvardsen, J. \& Kringlen, E. (1993). 'True' schizotypal personality disorder: a study of cotwins and relatives of schizophrenic probands. American Journal of Psychiatry 150, 1661-1667.

Venables, P. H. \& Rector, N. A. (2000). The content and structure of schizotypy: a study using confirmatory factor analysis. Schizophrenia Bulletin 26, 587-602.

Vollema, M. G. \& van den Bosch, R. J. (1995). The multidimensionality of schizotypy. Schizophrenia Bulletin 21, 19-31.
Wall, J. D. \& Pritchard, J. K. (2003). Haplotype blocks and linkage disequilibrium in the human genome. Nature Review Genetics $\mathbf{4}$, 587-597.

Williams, N. M., Preece, A., Spurlock, G., Norton, N., Williams, H. J., Zammit, S., O'Donovan, M. C. \& Owen, M. J. (2003). Support for genetic variation in neuregulin 1 and susceptibility to schizophrenia. Molecular Psychiatry 8, 485-487.

Yang, J. Z., Si, T. M., Ruan, Y., Ling, Y.S., Han, Y. H., Wang, X. L., Zhou, M., Zhang, H. Y., Kong, Q. M., Liu, C., Zhang, D. R., Yu, Y. Q., Liu, S. Z., Ju, G. Z., Shu, L., Ma, D. L. \& Zhang, D. (2003). Association study of neuregulin 1 gene with schizophrenia. Molecular Psychiatry 8, 706-709.

Zaykin, D. V., Westfall, P. H., Young, S. S., Karnoub, M. A., Wagner, M. J. \& Ehm, M. G. (2002). Testing association of statistically inferred haplotypes with discrete and continuous traits in samples of unrelated individuals. Human Heredity 53, 79-91.

Zhao, X., Shi, Y., Tang, J., Tang, R., Yu, L., Gu, N., Feng, G., Zhu, S., Liu, H., Xing, Y., Zhao, S., Sang, H., Guan, Y., St Clair, D. \& He, L. (2004). A case control and family based association study of the neuregulin 1 gene and schizophrenia. Journal of Medical Genetics 41, 31-34. 